\title{
Endovascular Treatment of Traumatic Pseudo Aneurysm of the Supraescapular Artery
}

\author{
Méndez $\mathrm{JC}^{1 *}$, Ana $\mathrm{P}^{2}$, Eduardo $\mathrm{F}^{1}$ and Javier $\mathrm{B}^{2}$
}

${ }^{1}$ Interventional Neuroradiology Unit, Department of Radiology, University Hospital Ramón y Cajal, Madrid, Spain

${ }^{2}$ Vascular and Interventional Radiology Unit, Department of Radiology, University Hospital Ramón y Cajal, Madrid, Spain

\begin{abstract}
Traumatic pseudoaneuryms of the supraescapular artery have been rarely reported. Management modalities poorly defined. Treatment options include simple observation, surgical intervention, and endovascular embolization alone or followed by surgery. We present a case of a traumatic pseudoaneurysm in the supraescapular artery in a 80 -year-old woman which was succesfully treated with endovascular embolization.
\end{abstract}

Keywords: Pseudo aneurysm; Supraescapular artery; Endovascular treatment

\section{Concept}

An 80-year-old woman with an atrial fibrillation has been treated with oral anticoagulant therapy. She presented with a history of upper right back pain after suffering a fall two months before with right clavicle fracture and multiple righ side rib fractures. Physical examination revealed a large, palpable, right sided, upper back subcutaneous heamatoma. A computed tomography (CT) scan revealed an extensive haematoma in the subcutaneous soft tissue of the right posterior chest wall, with a contrast-enhanced nodule into it, suggesting acute bleeding or pseudo aneurysm (Figure 1).

Selective right subclavian angiography demonstrated a pseudoaneurysm in the right supraescapular artery (Figure 2A). A decision was made to treat the pseudoaneurysm with selective embolization. A 6-french, $90 \mathrm{~cm}$-long sheat (Arrow International, Reading, PA, USA) was placed in the right subclavian artery, and the tip of a 5-French diagnostic catheter (JB-2, Cordis Corporation, Bridgewater, NJ, USA) was positioned in the proximal thyrocervical trunk as guiding catheter. A Rebar-14 microcatheter (Covidien, Irvine, CA, USA) with a 0.014-inch micro-guide wire (Synchro 14, Stryker, Kalamazoo, MI, USA) was advanced in a coaxial fashion through the 5-French catheter to reach the supraescapular artery distal to the pseudoaneurysm.

A total of $4 \mathrm{ml}$. of high-density liquid embolic agent (Onyx 500-HD, Covidien, Irvine, CA, USA) were injected through the microcatheter, and the pseudoaneurysm was succesfully occluded (Figure 2B). The patient was discharged two weeks after the procedure, and CT 30 days after injury showed almost complete resolution of the haematoma. Twelve months later, a control colour Doppler sonography confirmed the complete occlusion of the pseudaneurysm.

The suprascapular artery (or transverse scapular artery) is usually a branch of the thyrocervical trunk of the subclavian artery that supplies the supraspinatus, sternocleidomastoid and subclavius muscles. Some reports have described an abnormal origin of the suprascapular artery [1].

Pseudoaneurysms of subclavian or axillary arteries or their branches have been described as a sequelae of trauma or iatrogenic injuries. In these cases, treatment options include simple observation, surgical intervention, and endovascular embolization alone or followed by surgery $[2,3]$.
Traumatic pseudoaneuryms of the supraescapular artery have been rarely described, with only one previous case reported. Prater et al. [4] described a left supraescapular artery traumatic pseudoaneurysm which they treated with coil occlusion of the parent artery to prevent backflow from collateral vessels. Zardi et al. [5], described an non-traumatic aneurysm of the right supraescapular artery arising directly from the subclavian artery, which was succesfully treated with endovascular embolization of the aneurysm, the parent artery and their collaterals with high-viscosity agent (Onyx Hd-500).

Selective embolization of pseudoaneuryms with Onyx has proven to be an effective technique for achieving complete occlusion of pseudoaneurysms, with no recurrences during follow-up [6,7]. In

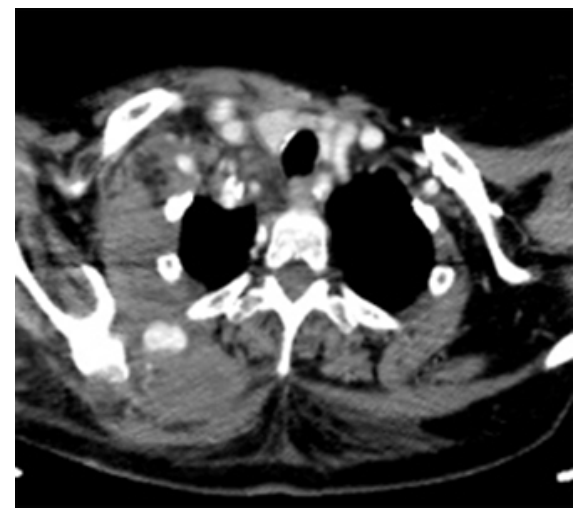

Figure 1: Axial contrast-enhanced CT scan shows a huge hematoma in the right posterior chest wall with a pseudoaneurysm enhanced during arterial phase of intravenous contrast agent injection.

*Corresponding author: Méndez JC, Interventional Neuroradiology Unit, Department of Radiology, University Hospital Ramón y Cajal, Madrid, Spain, Tel: 911256407; E-mail: jmendezce@gmail.com

Received July 16, 2015; Accepted January 21, 2016; Published January 29, 2016

Citation: Méndez JC, Ana P, Eduardo F, Javier B (2016) Endovascular Treatment of Traumatic Pseudo Aneurysm of the Supraescapular Artery. J Vasc Med Surg 4: 249. doi:10.4172/2329-6925.1000249

Copyright: @ 2016 Méndez JC, et al. This is an open-access article distributed under the terms of the Creative Commons Attribution License, which permits unrestricted use, distribution, and reproduction in any medium, provided the original author and source are credited. 
Citation: Méndez JC, Ana P, Eduardo F, Javier B (2016) Endovascular Treatment of Traumatic Pseudo Aneurysm of the Supraescapular Artery. J Vasc Med Surg 4: 249. doi:10.4172/2329-6925.1000249

Page 2 of 2

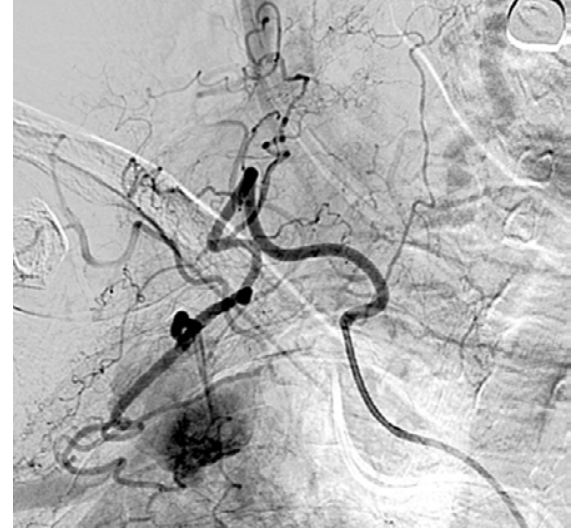

Figure 2A: Digital subtraction angiography in the arterial phase shows contrast extravasation from the right supraescapular artery, consistent with pseudo aneurysm.

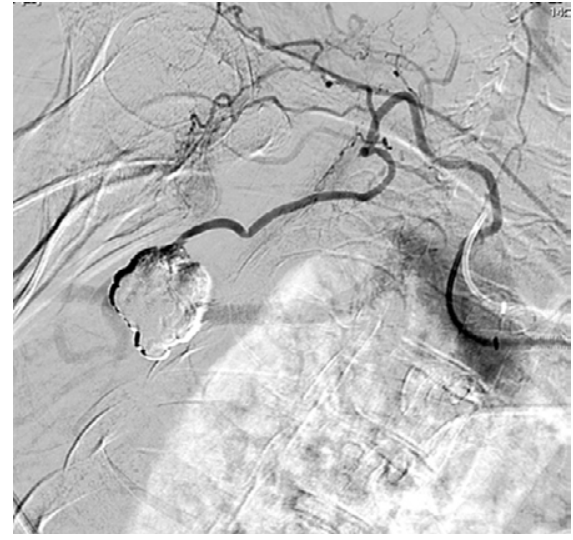

Figure 2B: Selective angiography of right cost cervical trunk after embolization shows complete obliteration of the pseudo aneurysm. our experience, if complete occlusion of the aneurysm is achieved with Onyx, it is no neccesary to oclude both the aneurysm and all the collaterals at one time to prevent aneurysm recanalization. Intraaneurysmal controlled injection of high-viscosity Onyx allows total pseudoaneurysm occlusion and parent artery preservation in most cases, with no further risk of aneurysm recanalization from collateral arteries.

\section{References}

1. Mishra S, Ajmani ML (2003) Anomalous Origin of Suprascapular Artery: A Case Report. J Anat Soc India 52: 180-182.

2. Sueyoshi E, Sakamoto I, Nakashima K, Minami K, Hayashi K (2005) Visceral and peripheral arterial pseudoaneurysms. AJR Am J Roentgenol 185: 741749 .

3. Tulsyan N, Kashyap VS, Greenberg RK, Sarac TP, Clair DG, et al. (2007) The endovascular management of visceral artery aneurysms and pseudoaneurysms. J Vasc Surg 45: 276-283.

4. Prater S, Marichal DA, Rees C (2010) Endovascular management of suprascapular artery pseudoaneurysm. Proc (Bayl Univ Med Cent) 23: 24-26.

5. Zardi EM, Bucci F, Zardi DM, Capoano R, Salvatori FM, et al. (2009) Anomalous origin and aneurysm of the suprascapular artery: the first case observed. BM Case Rep.

6. Grijalba FU, Esandi MC, Iriberri JB (2008) Embolization in peripheral artery bleeding with Onyx. Radiologia 50: 503-508.

7. Vanninen RL, Manninen I (2007) Onyx a new liquid embolic material for peripheral interventions: preliminary experience in aneurysm, pseudoaneurysm, and pulmonary arteriovenous malformation embolization. Cardiovasc Intervent Radiol 30: 196-200. 